\title{
Zinc ion adsorption on carbon nanotubes in an aqueous solution
}

\author{
A. Ansari' ${ }^{1}$ M.A. Mehrabian', H. Hashemipour ${ }^{2}$ \\ ${ }^{1}$ Department of Mechanical Engineering \\ ${ }^{2}$ Department of Chemical Engineering, Shahid Bahonar University of Kerman, Iran \\ "Corresponding author: e-mail: ma_mehrabian@alum.mit.edu
}

\begin{abstract}
The literature devoted to numerical investigation of adsorption of heavy metal ions on carbon nanotubes is scarce. In this paper molecular dynamics is used to simulate the adsorption process and to investigate the effect of the influencing parameters on the rate of adsorption. The predictions of the molecular dynamics simulation show that the adsorption process is improved with increasing the temperature, $\mathrm{pH}$ of solution, the mass of nanotubes, and surface modification of CNT using hydroxyl and carboxyl functional groups. The results predicted by the model are compared with the experimental results available in the literature; the close agreement validates the accuracy of the predictions. This study reveals that the water layers around the carbon nanotubes and the interaction energies play important roles in the adsorption process. The study also shows that electrostatic force controls the attraction of zinc ions on the nanotube sidewall.
\end{abstract}

Keywords: Adsorption, Molecular dynamics simulation, Heavy metals, Electrostatic force, Interaction energy, Functional groups.

\section{INTRODUCTION}

The pollution of water with some heavy metals like copper, lead, and zinc has attracted researchers' attention. Almost all heavy metal ions have a long life presence in the environment. Among the heavy metals zinc has extensive potential in water pollution. Zinc has very slow metal mineralization process. The methods such as reverse osmosis, evaporation, ion exchange, and adsorption; have been used for zinc removal from wastewater. Using adsorbent materials such as activated carbon, fly ash, peat, sewage sludge ash, zeolite, biomaterials, recycled alum sludge, manganese oxides, and resins has advantages like low cost, good recovery, and high efficiency 1 .

Recently, Carbon Nano Tubes (CNT's) have demonstrated high capacity for adsorbing a wide variety of heavy metal pollutants. The experimental investigations showed that many factors can influence the adsorption process. Some of these important factors are CNT surface properties, the CNT mass, solution $\mathrm{pH}$, and solution temperature.

The chemical properties of the CNT surface can be modified using chemical and thermal treatment. The modified CNT surface contains the oxygen functional groups such as carboxyl $(-\mathrm{COOH})$, and carbonyl $(-\mathrm{CO})$ or hydroxyl $(-\mathrm{OH})$. After the modification, the zeta potential of CNT surface becomes more negative ${ }^{2-5}$. The zeta potential is a function of the charge of carbon atoms on the CNT surface. This negative charge on the CNT surface causes electrostatic interaction with heavy metal ions having the positive charge. The experimental study shows that the CNT adsorption capacity is improved after the modification ${ }^{4,6-10}$.

The experimental studies show that the amount of $\mathrm{Zn}^{2+}$ and other heavy metal ions adsorbed on CNTs are remarkably increased with increasing the temperature of the solution ${ }^{11-14}$. Increasing the temperature results in decreasing the viscosity of the solution. The ions can move and diffuse more easily in the solution and this explains why adsorption rate increases when the temperature is increased.

The $\mathrm{pH}$ of heavy metal ion solution is an important parameter in adsorption progress. Many investigations proved that the $\mathrm{pH}$ can affect the CNT adsorption capacities $^{2,4,9,15-20}$. The solution $\mathrm{pH}$ can affect the adsorption process in two ways: the CNT surface charge, and metal hydrolysis reactions. The results show that a negative charge exists on the CNT surface at high $\mathrm{pH}$. This negative charge can improve the adsorption process due to electrostatic force between the CNT and the cations. The studies also show that at $\mathrm{pH}>12$, the adsorption capacity of CNT is decreased because of the metal hydrolysis reactions with $\mathrm{H}^{+}$and $\mathrm{OH}^{-}$ions. A mixture of $\mathrm{M}^{2+}, \mathrm{M}(\mathrm{OH})^{+}, \mathrm{M}(\mathrm{OH})_{2}$, and $\mathrm{M}(\mathrm{OH})_{3}^{-1}$ exists in the solution. At low $\mathrm{pH}$ range $(2<\mathrm{pH}<7)$ the heavy metal ion is present in the form of $\mathrm{M}^{2+}$ and the CNT surface charge is either positive or negative, but very close to zero. At this range of $\mathrm{pH}$ there is also a competitive adsorption process between $\mathrm{M}^{2+}$ and $\mathrm{H}^{+}$ in the solution. Therefore, at low $\mathrm{pH}$ range the rate of adsorption process is small. In the medium $\mathrm{pH}$ range $(8<\mathrm{pH}<11$ the metal ions are present in the forms of $\mathrm{M}(\mathrm{OH})^{+}$, and $\mathrm{M}(\mathrm{OH})_{2}$. In this range, the maximum adsorption rate is observed for almost all heavy metals due to the electrostatic interaction between the metal ions and the CNT. At high $\mathrm{pH}$ range $(\mathrm{pH}>12)$, the metal ion forms the $\mathrm{M}(\mathrm{OH})_{3}^{-1}$ complex. This complex cannot be adsorbed to CNT surface which has the maximum negative charge at high $\mathrm{pH}$ range.

The aim of this paper is to study the adsorption of zinc ion as a pollutant on the surface of CNT and the effect of important parameters such as CNT surface modification, temperature, $\mathrm{CNT} /$ Zinc mass ratio and $\mathrm{pH}$ (in the range of 6-8) on the removal progress. A (6, 6) CNT with radius of $4.1 \AA$ was placed in a periodic computational box consisting of a zinc ion and water molecules. The length of the periodic water box is $29.42 \AA$. The number of water molecules depends on the length of the CNT. A parametric study is carried out using the MD simulation. The numerical results at different operating conditions are obtained. The analysis of these results helps to understand the dynamic properties of heavy metal ions adsorbed on the CNT. 


\section{THE SIMULATION METHODOLOGY}

\section{Potential models}

In this study water molecules, ions, and carbon atoms are considered as spherical rigid bodies. The potential model for the interaction between water molecules, zinc ions, and carbon atoms of CNT is expressed as follows: $U_{\text {Total }}=U_{v d w}+U_{\text {coulomb }}$

The terms $U_{v d W}$ and $U_{\text {coulomb }}$ in Equation 1 describe the van der Waals and electrostatic non-bonded interactions respectively:

$U_{v d w}=\sum_{i} \sum_{j>i} \varepsilon_{i j}\left[\left(\frac{\sigma_{i j}}{r_{i j}}\right)^{12}-2\left(\frac{\sigma_{i j}}{r_{i j}}\right)^{6}\right]$

$U_{\text {coulomb }}=\sum_{i} \sum_{j>i} \frac{q_{i} q_{j}}{4 \pi \varepsilon_{0} r_{i j}}$

In this paper a simple Lennard-Jones $12-6$ potential form is used for the simulation of vdW interaction. $\varepsilon$ and $\sigma$ are the well-depth and diameter of the potential respectively ${ }^{21} \cdot q_{i}$ and $q_{j}$ are the charges of atoms $i$ and $\mathrm{j}$, located at the center of respective atoms. For the computation of $\varepsilon$ and $\sigma$ between the unlike atoms, the Lorentz-Berthelot mixing rule can be used ${ }^{22}$ :

$\varepsilon_{i j}=\sqrt{\varepsilon_{i} \varepsilon_{j}}, \sigma_{i j}=\frac{\left(\sigma_{i}+\sigma_{j}\right)}{2}$

Table 1. Parameters used in the potential model

\begin{tabular}{|l|c|c|c|}
\hline \multicolumn{1}{|c|}{ Component } & $\varepsilon[\mathrm{kcal} / \mathrm{mol}]$ & $\begin{array}{c}\sigma \\
{[\AA]}\end{array}$ & $\begin{array}{c}\mathrm{Q} \\
\text { Electron unit }\end{array}$ \\
\hline Water[23] & 0.15 & 3.15 & 0 \\
\hline Zinc ion $^{\mathrm{a}}$ & 0.0125 & 1.96 & +2 \\
\hline Carbon[24] $^{2}$ & 0.055 & 3.4 & Section 2.3 \\
\hline
\end{tabular}

${ }^{a}$ AMBER force field

The Lennard-Jones parameters and partial charges used in the simulation are listed in Table 1. The point charge of the CNT carbon atoms has been calculated in section 2.3.

\section{Simulation method}

The zinc ions/water/CNT system is modeled using an in-house computer program written in the FORTRAN language. This code supports NVT (Isothermal) ensemble and uses Berendsen thermostat method to account for the temperature of the system ${ }^{25}$. In the Berendsen thermostat method, the particle velocity of the system at each step is rescaled by the $\lambda$ factor. The $\lambda$ factor is defined as [25]:

$\lambda=\left[1+\frac{\Delta t}{\tau_{t}}\left(\frac{T}{T_{0}}-1\right)\right]^{\frac{1}{2}}$

Where $\tau_{\mathrm{t}}$ is the user defined time constant (typically 0.5-5.0 ps), $\mathrm{T}$ the current temperature, $\mathrm{T}_{\mathrm{o}}$ the desired temperature and $\Delta \mathrm{t}$ the time step. In all simulations, the time step was chosen as $0.5 \mathrm{fs}$.

A periodic water box consisting of one cation, water molecules and CNT was considered. During the simulation, the Verlet algorithm was employed ${ }^{22}$. In every state, the code runs for $5 \times 10^{4}$ time steps, whereas the latter $5 \times 10^{3}$ time steps were used to calculate the results.

\section{Charge of the CNT carbon atoms}

The relation between the surface potential, $\varphi_{0}$, and the surface charge density, $\beta$, can be expressed $\mathrm{as}^{\mathbf{2 6}}$ :

$\varphi_{0}=\frac{\beta}{\epsilon_{0} \epsilon_{\mathrm{r}} \alpha}$

The Debye length is given by:

$\alpha^{2}=\frac{2000 \mathrm{~F}^{2}}{\epsilon_{0} \epsilon_{\mathrm{r}} \mathrm{RT}} \mathrm{I}$

It is assumed that the zeta potential, $£$, is equal to the surface potential. The zeta potential is a function of surface charge and can be determined experimentally using an electro-kinetic device. Lu et al. ${ }^{4}$ calculated the zeta potential of $\mathrm{CNT}$ at various $\mathrm{pH}$. If every carbon atom on the CNT surface is considered a single spherical body with radius $\mathrm{rc}$, the surface charge density, $\sigma$, can be defined as $^{26}$ :

$\beta=\frac{\mathrm{q}}{4 \pi \mathrm{r}_{\mathrm{c}}^{2}}$

Finally, using Equations 8 and 10, the point charge of carbon atom can be defined as:

$\mathrm{q}=4 \pi £ \epsilon_{0} \epsilon_{\mathrm{r}} \alpha \mathrm{r}_{\mathrm{c}}^{2}$

Table 2 shows the point charge of CNT carbon atoms and the related parameters.

Table 2. Experimental design and results for percentage removal of $\mathrm{Cr}(\mathrm{VI})$ ion by $\mathrm{NCN}$ resin

\begin{tabular}{|c|c|c|}
\hline parameter & unit & amount \\
\hline $\mathrm{q}$ & $\mathrm{e}$ & -0.0085 \\
\hline$\epsilon_{r}[26]$ & - & 78 \\
\hline$E[4]$ & $\mathrm{mv}$ & -20 \\
\hline$\alpha$ & $\mathrm{m}^{-1}$ & $2.71 \times 10^{+8}$ \\
\hline$\epsilon_{0}$ & $\mathrm{C}^{2} / \mathrm{Nm}^{2}$ & $8.85 \times 10^{-12}$ \\
\hline $\mathrm{R}$ & $\mathrm{J} / \mathrm{mol}^{2} \mathrm{~K}$ & 8.314 \\
\hline $\mathrm{T}$ & $\mathrm{K}$ & 298 \\
\hline $\mathrm{I}$ & $\mathrm{mole} / \mathrm{liter}$ & 0.0125 \\
\hline
\end{tabular}

\section{RESULTS AND DISCUSSION}

To investigate the effect of $\mathrm{pH}$, temperature, and the CNT mass, the MD code runs at various conditions, but in all conditions, the length of the simulation box, the location and type of CNT, and the first location of zinc ion were the same.

\section{Influence of $\mathrm{CNT} / \mathrm{Zinc}$ mass ratio}

In order to study the effect of $\mathrm{CNT} /$ Zinc mass ratio, three different ion/CNT mass ratios were considered. The CNTs $(6,6)$ with different lengths are used in this study. In all cases, the zinc ion is located 11away from CNT sidewall. The details are listed in Table 3. The snapshots of the simulation at the start and the final time are shown in Fig. 1.

Fig. 2 demonstrates the minimum distance between zinc ion and CNT sidewall during the simulation time.

Table 3. ANOVA and estimated regression coefficients for $\mathrm{Cr}(\mathrm{VI})$ ion removal by $\mathrm{NCN}$ resin

\begin{tabular}{|c|c|c|c|c|}
\hline Case & $\begin{array}{c}\text { Number of } \\
\text { carbon } \\
\text { atoms }\end{array}$ & $\begin{array}{c}\text { CNT } \\
\text { Length } \\
(\AA)\end{array}$ & $\begin{array}{c}\text { Ion-CNT } \\
\text { mass ratio } \\
\left(\mathrm{mg}^{-1}\right)\end{array}$ & $\mathrm{N}_{\text {water }}$ \\
\hline 1 & 140 & 14.77 & 38.7 & 2372 \\
\hline 2 & 168 & 17.23 & 32.2 & 2272 \\
\hline 3 & 192 & 19.70 & 28.2 & 2268 \\
\hline
\end{tabular}




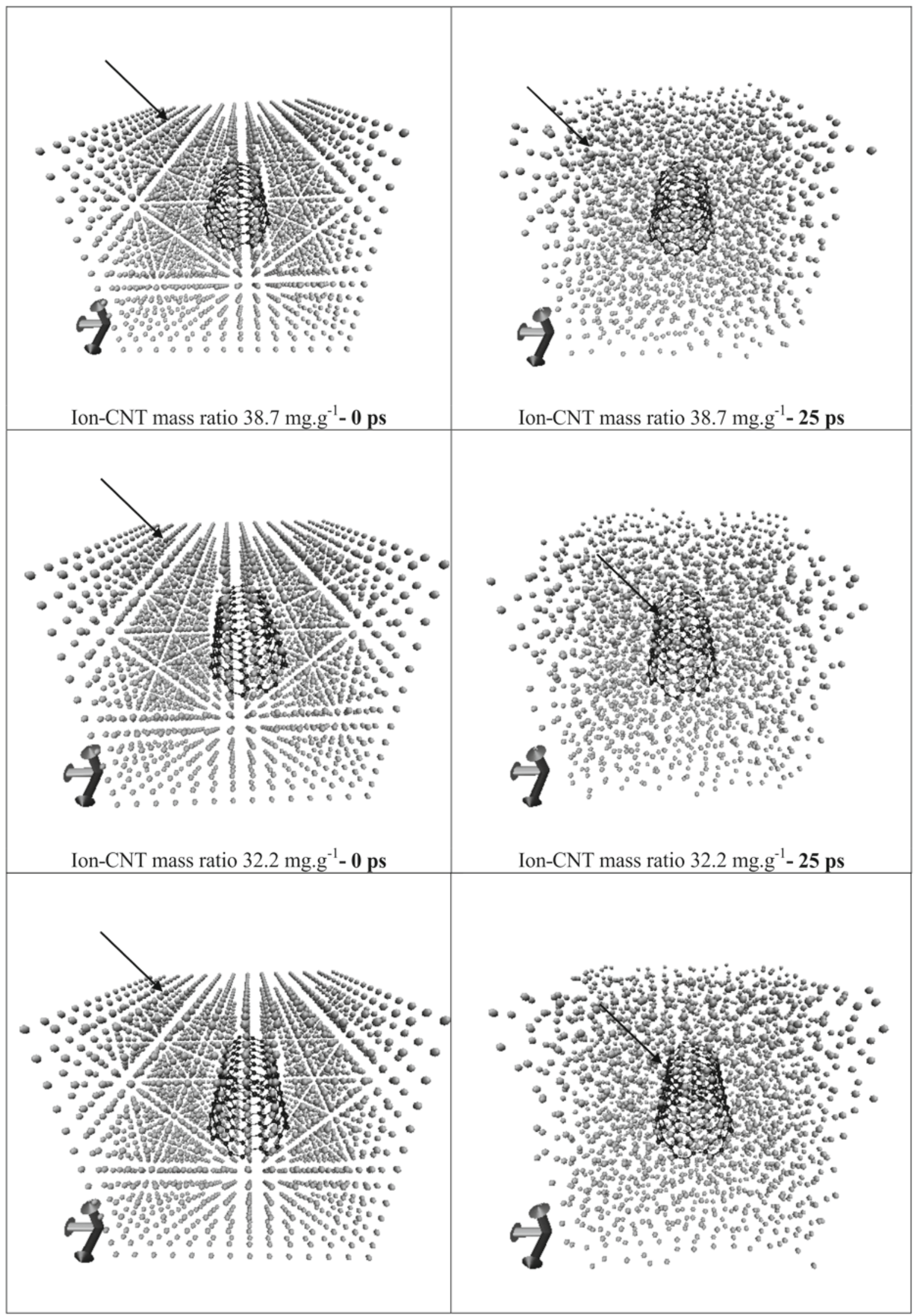

Figure 1. Snapshots of simulation configurations for CNT $(6,6)$, red denotes zinc ion, blue denotes water molecules, and black denotes CNT atoms

The results show that the adsorption process did not occur in ion-CNT mass ratio of $38.7 \mathrm{mg} . \mathrm{g}^{-1}$. In ion-CNT mass ratio of $32.2 \mathrm{mg.g} \mathrm{g}^{-1}$, the zinc ion is adsorbed on CNT surface after $23.65 \mathrm{ps}$. In ion-CNT mass ratio of $28.2 \mathrm{mg} \cdot \mathrm{g}^{-1}$, with maximum length and number of carbon atoms, the adsorption process rapidly starts after the equilibrium steps. The final distance between zinc ion and the CNT sidewall after the adsorption process is equal to $1.92 \AA$ for ion-CNT mass ratios of 32.2 and $28.2 \mathrm{mg} \cdot \mathrm{g}^{-1}$.

For more details about the adsorption process, an overview on the interaction energy of the system is necessary. The total interaction energy of the system can be expressed as: 


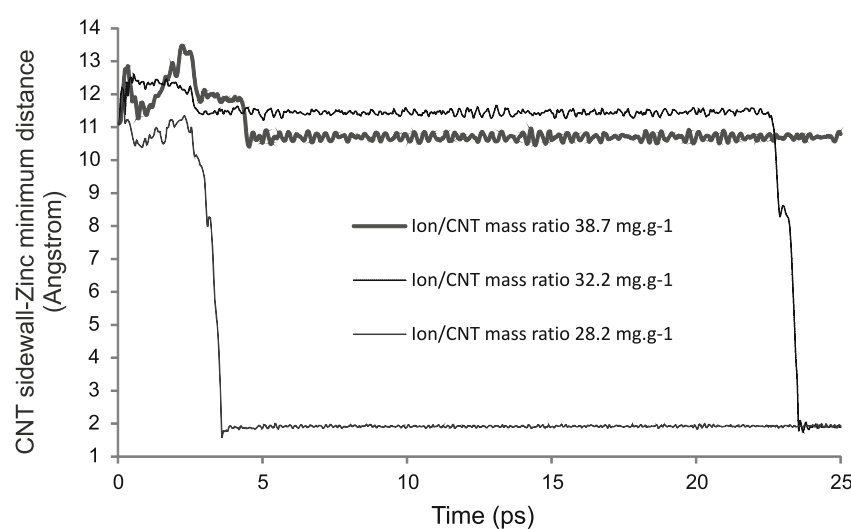

Figure 2. The distance between zinc ion and CNT wall side as a function of simulation time

$\mathrm{E}_{\text {Total }}=\mathrm{E}_{\text {water - water }}+\mathrm{E}_{\text {water - ion }}+\mathrm{E}_{\text {water }-\mathrm{CNT}}+\mathrm{E}_{\mathrm{CNT} \text { - ion }}$

The important energy term for the adsorption process is the interaction energy between an ion and CNT $\left(\mathrm{E}_{\mathrm{CNT} \text {-ion }}\right)$. Using Equation 12 the interaction energy between zinc ion and CNT is defined as:

$\mathrm{E}_{\mathrm{CNT} \text { - ion }}=\mathrm{E}_{\text {Total }}-\mathrm{E}_{\mathrm{water}}$ - water $-\mathrm{E}_{\mathrm{water}}$ - ion $-\mathrm{E}_{\mathrm{water}}$ - CNT

CNT-zinc ion interaction energy as a the function of time is shown in Fig. 3. This figure shows that the interaction energy between the CNT and zinc ion is increased with increasing the number of the CNT carbon atoms. There is a strong attractive interaction energy between CNT and zinc ion in ion-CNT mass ratio of $28.2 \mathrm{mg} \cdot \mathrm{g}^{-1}$. The interaction energy is divided into two parts: the $\mathrm{vdW}$ interaction energy and the electrostatic interaction energy. The interaction energy is the sum of these energies. Fig. 4 demonstrates the vdW and electrostatic interaction energy between CNT and zinc ion for three ion/CNT mass ratios. It is clear that the

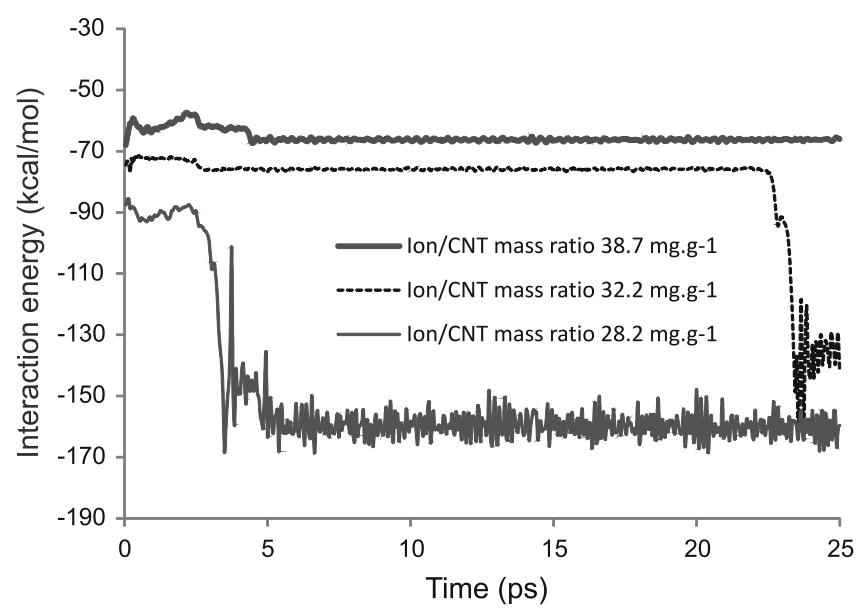

Figure 3. CNT-zinc ion interaction energy

electrostatic energy is almost equal to the total energy when large distances exist between zinc ion and CNT surface. This condition results in an attractive force between the metal ions and carbon atoms. The vdW energy only appears when the distances are short and it results in a repulsive force between the CNT and the metal ion. Finally, the zinc ion stops at a short distance to the CNT sidewall where the repulsive and attractive forces due to the $\mathrm{vdW}$ and electrostatic interaction become equal.

The RDF peaks of water molecules around the CNT are illustrated in Fig. 5. The results demonstrate that the water molecules form several layers (RDF peaks)

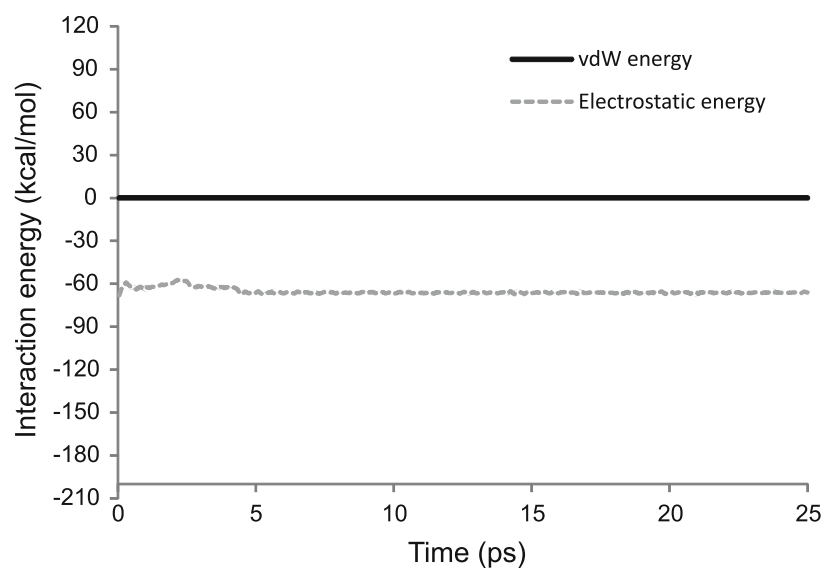

(a)

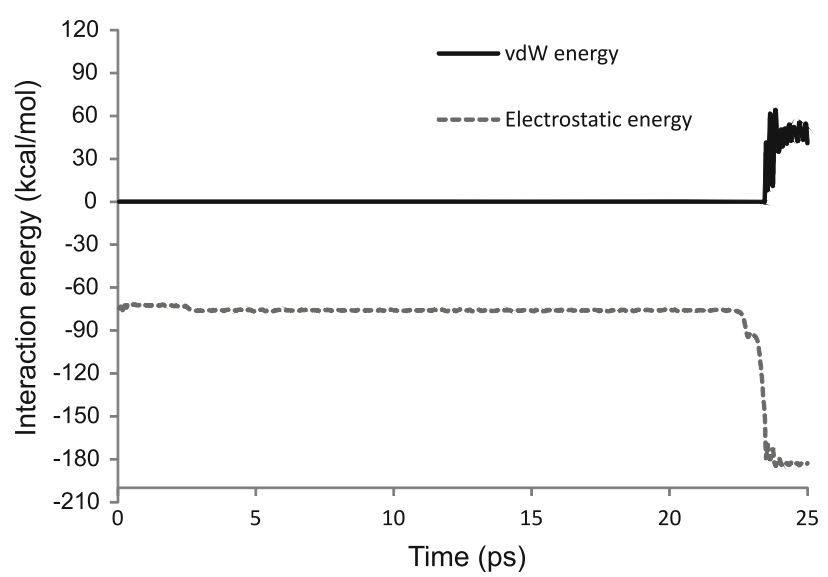

(b)

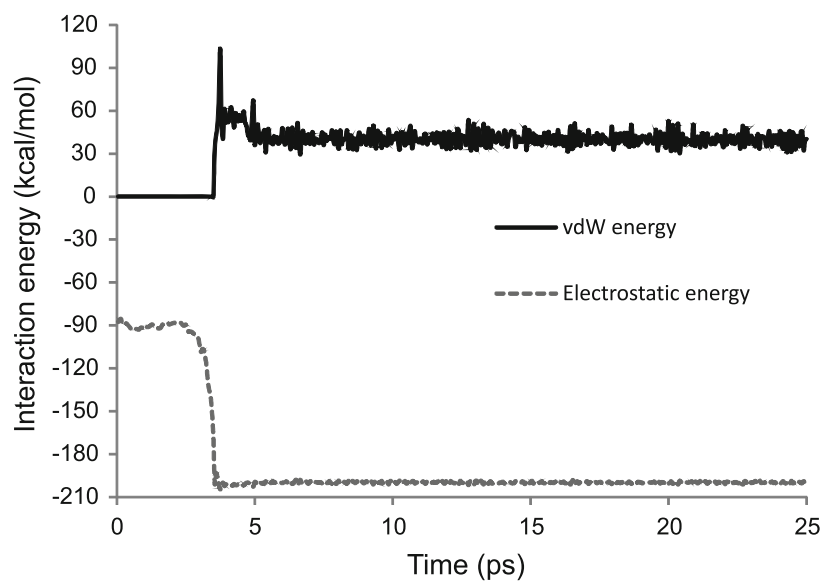

(c)

Figure 4. The vdW and the electrostatic interaction energies between CNT and zinc ion, zinc ion/CNT mass ratio: $38.7 \mathrm{mg} \cdot \mathrm{g}^{-1}$ (b) $32.2 \mathrm{mg} \cdot \mathrm{g}^{-1}$ (c) $28.2 \mathrm{mg} \cdot \mathrm{g}^{-1}$

around CNT sidewall. These high-density layers can prevent ion adsorption to the CNT surface. This is clear that every water layer located at a farther distance from the CNT sidewall is more important, because at far distances from the CNT, the attractive electrostatic force between CNT and ion is small. In ion/CNT mass ratio of $38.7 \mathrm{mg} . \mathrm{g}^{-1}$, the attractive force between CNT and ion cannot overcome the repulsive force acting on zinc ion by peaks located in far distances from CNT sidewall. Therefore, the adsorption process does not occur in this case. 


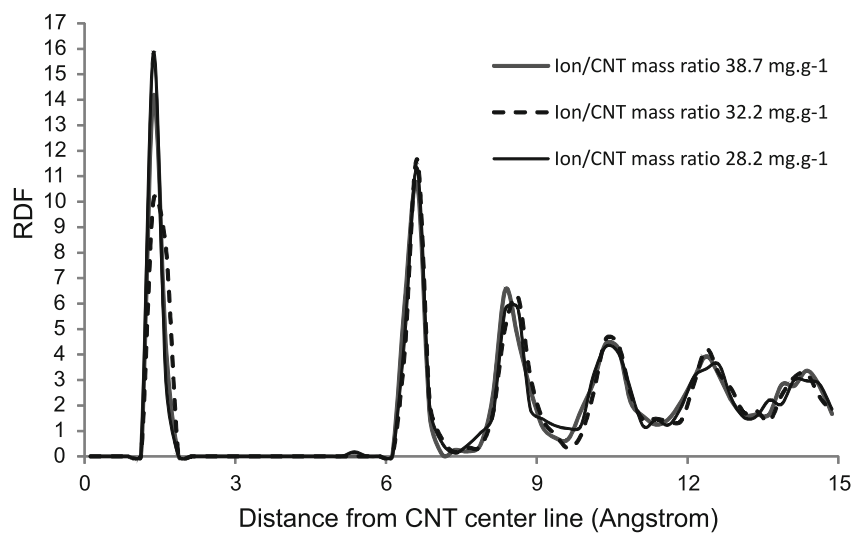

Figure 5. The RDF curves for different ion/CNT mass ratios

\section{Influence of $\mathbf{p H}$}

In this paper, the effect of $\mathrm{pH}$ was studied in the range of $6<\mathrm{pH}<8$, because the metal ion is available in the form of $\mathrm{M}^{2+}$ in the solution in this range of $\mathrm{pH}$. The simulation program runs under the conditions similar to Case 2 in Table 3 for $\mathrm{pH}=6,7$, and 8 and temperature of $298 \mathrm{~K}$. The zeta potential for $\mathrm{pHs}$ of 8 , and 6 have been measured as $-30 \mathrm{mv}$, and $-17.5 \mathrm{mv}$ respectively ${ }^{4}$. Using the theoretical method presented in section 2.3, the point charges of CNT carbon atoms were calculated as -0.0127 e, and -0.0074 e respectively. Fig. 6 shows the zinc ion-CNT sidewall distance during simulation time. The results demonstrated that by increasing the $\mathrm{pH}$ of the solution, the adsorption process occurs faster. It is clear that with increasing the $\mathrm{pH}$ of the solution, the point charge of CNT carbon atom increases. The CNT, which has more negative surface charge, can attract the positive ion easily. The change of $\mathrm{pH}$ cannot affect the water layer around the ion because the only interaction energy between water molecules and CNT is the vdW energy and this energy is not a function of the CNT surface charge.

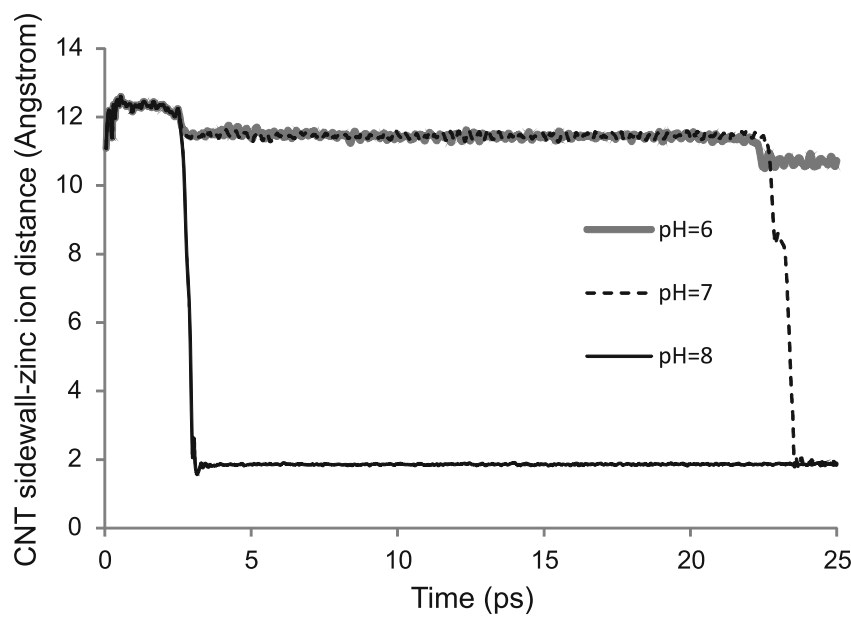

Figure 6. The zinc ion-CNT sidewall distance for $\mathrm{pH}=6,7$, and 8

\section{Influence of temperature}

To investigate the effect of the solution temperature on the adsorption process, the simulation program runs at temperatures of $298 \mathrm{~K}, 313 \mathrm{~K}$, and $338 \mathrm{~K}$ when $\mathrm{pH}=7$. The operating conditions are the same as Case 2 in Table 3. The zinc ion-CNT sidewall distances for three different temperatures are shown in Fig. 7. This figure shows that with increasing temperature, the time for adsorbing zinc ion to the CNT sidewall is reduces.

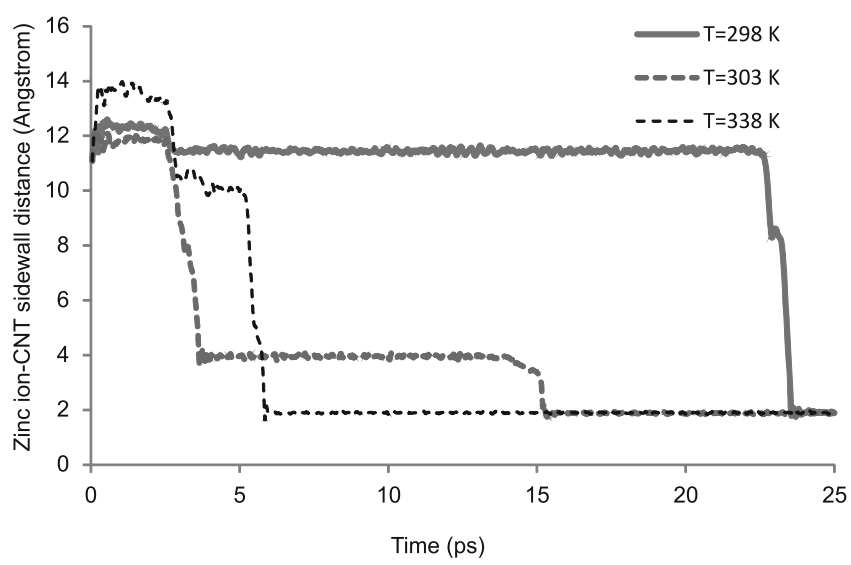

Figure 7. The zinc ion-CNT sidewall distance for $\mathrm{T}=298 \mathrm{~K}$, $303 \mathrm{~K}$, and $338 \mathrm{~K}$

Fig. 8 demonstrates the radial distribution function (RDF) of water molecules around the CNT centerline. The first peak of RDF occurs to water molecules inserted to CNT during simulation time. The most important peaks in adsorption process are those located outside the CNT. The second, third, and fourth peaks of water molecules around CNT are located in distances of $2.4 \AA$, $4.3 \AA$, and $6.7 \AA$ away from the CNT sidewall.

The ion movement towards the CNT due to electrostatic interaction is slowed down by the high-density water layers and in some conditions may be completely hindered. In large distances from the CNT sidewall, the maximum amount of water density occurs at the temperature of $298 \mathrm{~K}$. The differences in water density around the CNT at different temperatures, change the ion adsorption feature as shown in Fig. 7.

Eventually the RDF peaks located far from CNT are smaller at low temperatures. That is the reason why at higher temperatures the ion can approach the CNT more easily.

\section{Influence of the CNT modification}

Surface modification of the CNT by chemical agents like $\mathrm{HNO}_{3}, \mathrm{NaClO}$ and $\mathrm{HCl}$ forms some functional groups including carboxyl $(-\mathrm{COOH})$ and hydroxyl $(-\mathrm{OH})$ on the CNT surface. Fig. 9 shows a configuration of carboxyl and hydroxyl groups bonded to the CNT. To investigate the effect of these functional groups on the CNT surface, we simulated the adsorption process for the CNT with hydroxyl $(-\mathrm{OH})$ and the CNT with carboxyl $(-\mathrm{COOH})$ functional groups on their surface and then compared the results with those corresponding to the adsorption

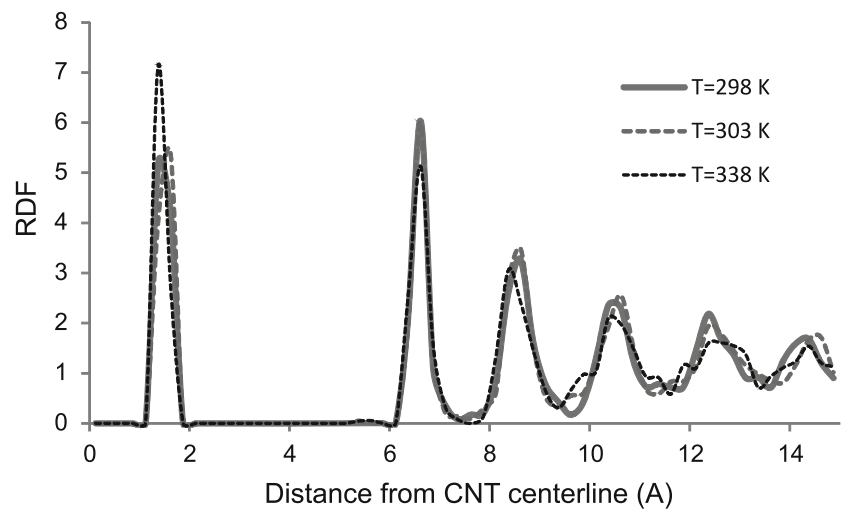

Figure 8. The radial distribution function (RDF) of water molecules around CNT centerline 
process for the CNT without functional group at $\mathrm{pH}=7$, and temperature of $298 \mathrm{~K}$. The operating conditions are the same as Case 2 in Table 3. The potential parameters and geometrical characteristics used for the simulation of the functional groups are presented in Tables 4, and 5.

Table 4. The potential parameters and geometrical characteristics used for the hydroxyl functional group

\begin{tabular}{|c|c|}
\hline \multicolumn{2}{|c|}{ Hydroxyl $^{a}$} \\
\hline \multicolumn{2}{|c|}{ Length $(\AA)$} \\
\hline $\mathrm{C}_{\mathrm{CNT} T} \mathrm{O}$ & 1.35 \\
\hline $\mathrm{O}-\mathrm{H}$ & 0.96 \\
\hline \multicolumn{2}{|c|}{ Angles (degree) } \\
\hline $\mathrm{C}_{\mathrm{CNT}}-\mathrm{O}-\mathrm{H}$ & 113 \\
\hline \multicolumn{2}{|c|}{ Potential parameters } \\
\hline$\sigma_{\circ}, \AA$ & 3.07 \\
\hline$\overline{\sigma_{\mathrm{H}}, \AA}$ & 0.0 \\
\hline$\varepsilon_{0}, \mathrm{kcal} / \mathrm{mol}$ & 0.21 \\
\hline$\varepsilon_{\mathrm{H}}, \mathrm{kcal} / \mathrm{mol}$ & 0.0 \\
\hline$q_{0}, e$ & -0.03 \\
\hline$q_{H}, e$ & -0.57 \\
\hline
\end{tabular}

${ }^{\mathrm{a} A M B E R}$ force field

Fig. 10 demonstrates the time history of the ion-CNT sidewall distance for the CNT with the hydroxyl group, the CNT with the carboxyl group, and the CNT without the functional groups. The results show that the presence of hydroxyl and carboxyl groups on CNT surface can improve the adsorption process very significantly. Comparing the hydroxyl and carboxyl functional groups reveals that the hydroxyl group can improve the CNT adsorption capacity more than carboxyl group. This is due to the presence of the positive atoms in the carboxyl group that decreases the attractive force between zinc ion and the carboxyl negative sites. The vdW and electrostatic energies between zinc ion and CNT are shown in Fig. 11. The strong electrostatic interaction energy can be observed between zinc ion and CNT surface due to the presence of hydroxyl group. Fig. 12 demonstrates the final configuration of CNT-hydroxyl and zinc ion after the adsorption.
Table 5. The potential parameters and geometrical characteristics used for the carboxyl functional group

\begin{tabular}{|c|c|}
\hline \multicolumn{2}{|c|}{ Carboxyl $^{b}$} \\
\hline \multicolumn{2}{|c|}{ Length $(\AA)$} \\
\hline $\mathrm{C}_{\mathrm{CNT} T} \mathrm{C}$ & 1.52 \\
\hline $\mathrm{C}=\mathrm{O}$ & 1.23 \\
\hline $\mathrm{C}-\mathrm{O}$ & 1.36 \\
\hline $\mathrm{O}-\mathrm{H}$ & 0.95 \\
\hline \multicolumn{2}{|c|}{ Angles (degree) } \\
\hline $\mathrm{C}_{\mathrm{CNT}}-\mathrm{C}=\mathrm{O}$ & 121 \\
\hline $\mathrm{C}_{\mathrm{CNT}-\mathrm{C}-\mathrm{O}}$ & 116 \\
\hline $\mathrm{C}-\mathrm{O}-\mathrm{H}$ & 113 \\
\hline \multicolumn{2}{|c|}{ Potential parameters } \\
\hline$\sigma_{\mathrm{c}}, \AA$ & 3.75 \\
\hline$\sigma_{\circ}, \AA(=0)$ & 2.96 \\
\hline$\sigma_{0}, \AA(-O)$ & 3.0 \\
\hline$\sigma_{\mathrm{H}}, \AA$ & 0 \\
\hline$\varepsilon_{\mathrm{c}}, \mathrm{kcal} / \mathrm{mol}$ & 0.105 \\
\hline$\varepsilon_{0}, \mathrm{kcal} / \mathrm{mol}(=\mathrm{O})$ & 0.21 \\
\hline$\varepsilon_{0}, \mathrm{kcal} / \mathrm{mol}(-\mathrm{O})$ & 0.17 \\
\hline$\varepsilon_{\mathrm{H}}, \mathrm{kcal} / \mathrm{mol}$ & 0.0 \\
\hline$q_{c}, e$ & 0.55 \\
\hline$q_{0}, e(=0)$ & -0.50 \\
\hline$q_{0}, e(-O)$ & -0.58 \\
\hline $\mathrm{q}_{\mathrm{H}}, \mathrm{e}$ & 0.45 \\
\hline
\end{tabular}

${ }^{\mathrm{b}}$ OPLSAA force field

In order to compare the simulation data with the available experimental results, the maximum ion/CNT mass ratio needed for the occurrence of the adsorption process are found by running the program with different CNT masses (CNT carbon atoms) at $\mathrm{pH}=7$, and the temperature of $298 \mathrm{~K}$. The results were then compared with the experimental results obtained by [4, and 5] and presented in Table 6. This comparison shows that the models containing functional groups are in closer agreement with the experimental data.

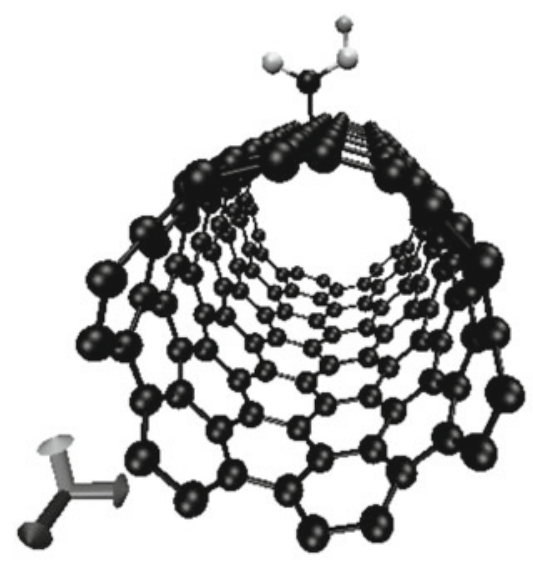

(a)

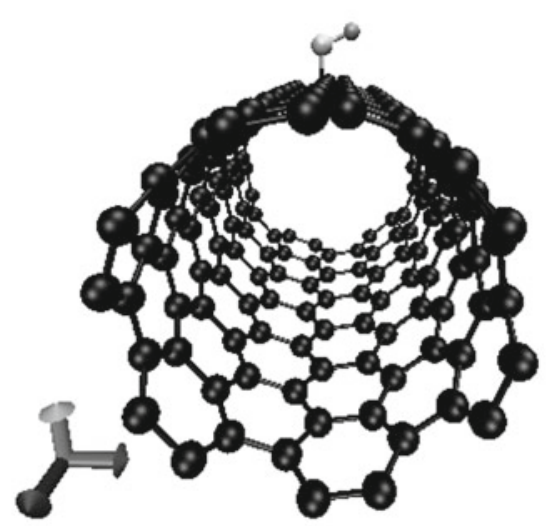

(b)

Figure 9. Functional groups bonded to CNT (a) carboxyl group (b) hydroxyl group; yellow denotes oxygen atoms, green denoted hydrogen atoms, and black denotes Carbon atoms 
Table 6. The maximum ion/CNT mass ratio for the adsorption process at $\mathrm{pH}=7$, and $\mathrm{T}=298 \mathrm{~K}$

\begin{tabular}{|l|c|c|c|}
\hline Sorbent & $\begin{array}{c}\text { Maximum lon/CNT } \\
\text { mass ratio }\left(\mathrm{mg}^{-1} \mathrm{~g}^{-}\right.\end{array}$ & Conditions & Ref \\
\hline CNT & 33.2 & $\mathrm{pH}=7.0, \mathrm{~T}=289 \mathrm{~K}$ & This work \\
\hline CNT with Hydroxyl F. G. & 36.7 & $\mathrm{pH}=7.0, \mathrm{~T}=289 \mathrm{~K}$ & This work \\
\hline CNT with Carboxyl F. G. & 38.6 & $\mathrm{pH}=7.0, \mathrm{~T}=289 \mathrm{~K}$ & This work \\
\hline CNT(modified with $\mathrm{NaClO}_{\text {) }}$ & 39.5 & $\mathrm{pH}=7.0, \mathrm{~T}=289 \mathrm{~K}$ & {$[4]$} \\
\hline CNT(modified with $\mathrm{HNO}_{3}$ ) & 40.0 & $\mathrm{pH}=7.0, \mathrm{~T}=289 \mathrm{~K}$ & {$[5]$} \\
\hline
\end{tabular}

F. G.: Functional group

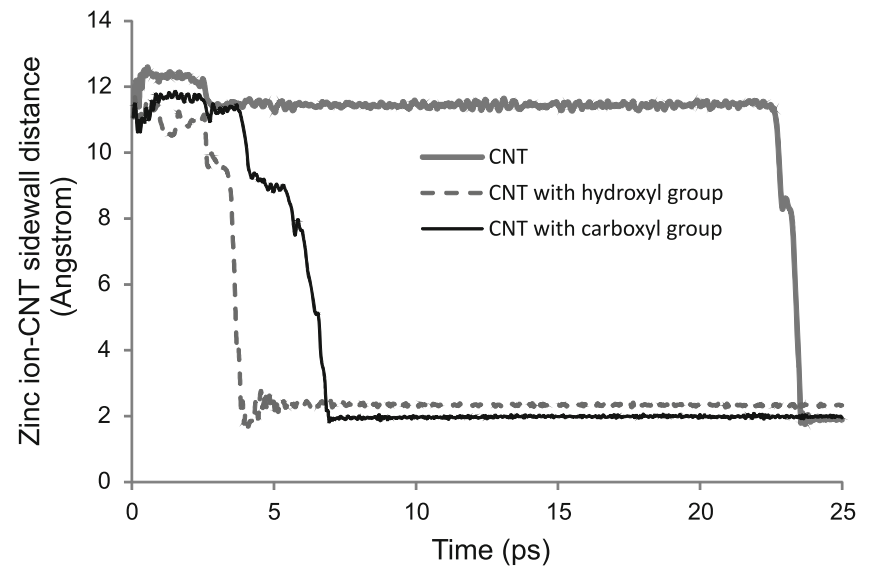

Figure 10. The effect of functional groups on zinc ion adsorption to $\mathrm{CNT}$ sidewall

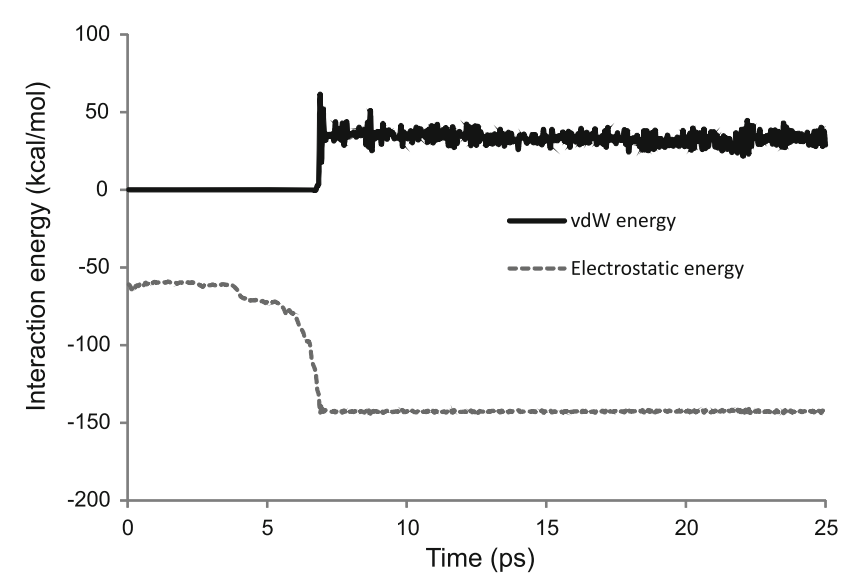

(a)

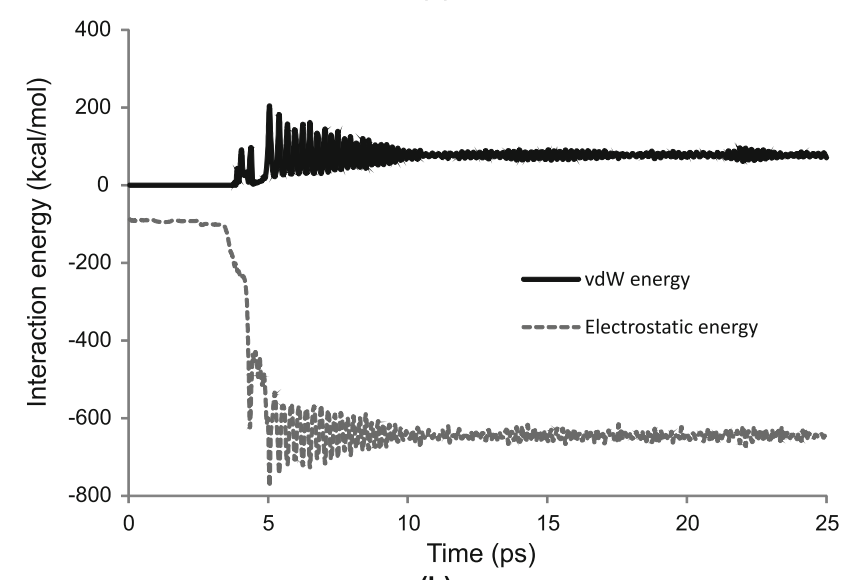

(b)

Figure 11. The vdW and the electrostatic interaction energies between CNT and zinc ion, CNT with : (a) carboxyl group (b) hydroxyl group

\section{CONCLUSIONS}

This paper applied molecular dynamics simulation to investigate the sorption behavior of zinc ion in the water on CNT surface. This study shows the effect of the parameters including $\mathrm{pH}$ and the temperature of

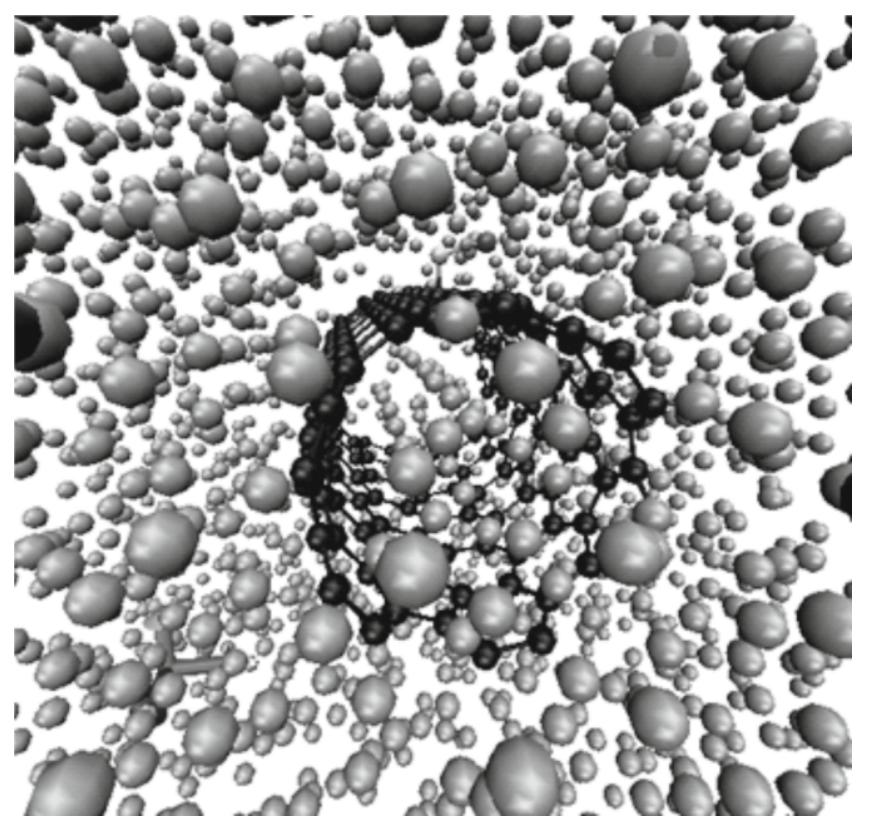

Figure 12. Snapshots of simulation configurations of zinc ion adsorption on modified CNT $(6,6)$, red denotes zinc ion, blue denotes water molecules, yellow denotes oxygen atom of hydroxyl group, green denoted hydrogen atom of hydroxyl group, and black denotes CNT atoms

the solution, and CNT/Zinc mass ratio on the rate of the adsorption process. The rate of adsorption can be improved with increasing the mass ratio. The mass ratio can increase the attractive electrostatic energy between $\mathrm{CNT}$ and zinc ion. Increasing the temperature of solution affects the water layer arrangement around the ion. The ion can pass easily from water layer in high temperature and therefore, the adsorption rate is increased. The point charge of CNT carbon atoms is a function of $\mathrm{pH}$ of solution. The amount of the negative charge of the CNT has direct relation with $\mathrm{pH}$. The more negatively charged CNT causes a stronger attractive force. One of the important ways to increase the CNT adsorption capacity was the modification of the CNT Surface. The results reveal that the hydroxyl and carboxyl functional groups can increase the adsorption process rate. This investigation confirms that increasing $\mathrm{pH}$, the temperature, the CNT mass, and the modification of the CNT are the possible ways to control the adsorption properties.

\section{NOMENCLATURE}

\section{Abbreviations}

MD Molecular dynamics

RDF Radial distribution function

vdW van der Waals

$\mathrm{U}_{\text {total }} \quad$ Total potential energy, $\mathrm{kcal} / \mathrm{mol}$

$\mathrm{U}_{\mathrm{vdW}} \quad$ Van der Waals energy, $\mathrm{kcal} / \mathrm{mol}$ 
$\mathrm{U}_{\text {coulomb }}$ Electrostatic energy, $\mathrm{kcal} / \mathrm{mol}$

\section{English symbol}

$\mathrm{E}_{\text {Total }} \quad$ Total interaction energy, $\mathrm{kcal} / \mathrm{mol}$

$\mathrm{E}_{\text {(water-water) }}$ Interaction energy between water molecules, $\mathrm{kcal} / \mathrm{mol}$

$\mathrm{E}_{\text {(water-ion) }}$ Interaction energy between water molecules and zinc ion, $\mathrm{kcal} / \mathrm{mol}$

$\mathrm{E}_{\text {(water-CNT) }}$ Interaction energy between water molecules and $\mathrm{CNT}$, $\mathrm{kcal} / \mathrm{mol}$

$\mathrm{E}_{(\mathrm{CNT} \text {-ion) }}$ Interaction energy between zinc ionand CNT, $\mathrm{kcal} / \mathrm{mol}$

F $\quad$ Farad constant, $\mathrm{C} / \mathrm{mol}$

I Concentration, mole/litr

$\mathrm{N}_{\text {water }} \quad$ Number of water molecules in simulation box

$\mathrm{q} \quad$ Atom point charge, e

R Gas constant, J/mol.K

T Temperature, $\mathrm{K}$

$\mathrm{T}_{\mathrm{o}} \quad$ Desired temperature, $\mathrm{K}$

$\mathrm{t}$ Time, $\mathrm{s}$

$r_{c} \quad$ Radius of CNT carbon atom, $\AA$

Greek symbols

$\AA \quad$ Angstrom, $10^{-10} \mathrm{~m}$

$\alpha \quad$ Debye length, $\mathrm{m}^{-1}$

$\beta \quad$ Surface charge density, $\mathrm{C} / \mathrm{m}^{2}$

$\varepsilon \quad$ Well-depth of potential, $\mathrm{kcal} / \mathrm{mol}$

$\varepsilon_{0} \quad$ Permittivity of free space, $8.8542 \times 10^{-12} \mathrm{C}^{2} \mathrm{~N}^{-1} \mathrm{~m}^{-2}$

$\epsilon_{\mathrm{r}} \quad$ Dielectric constant of solution

$\sigma \quad$ Diameter of the potential, $\AA$

$\tau \quad$ User defined time constant

$\varphi_{0} \quad$ Surface charge potential, $V$

$£ \quad$ Zeta potential, V

\section{units}

e

fs

ps

Electron unit, $1.6 \times 10^{-19} \mathrm{C}$

Femto second, $10^{-15} \mathrm{~s}$

Pico second $\left(10^{-12} \mathrm{~s}\right)$

\section{LITERATURE CITED}

1. Rao, G., Lu, Ch. \& Su, F. (2007). Sorption of divalent metal ions from aqueous solution by carbon nanotubes: A review. Separation and Purification Technology 58, 224-231. DOI: 10.1016/j.seppur.2006.12.006.

2. Wang, H.J., Zhou, A.L., Peng, F., Yu, H. \& Chen, L.F. (2007). Adsorption characteristic of acidified carbon nanotubes for heavy metal $\mathrm{Pb}(\mathrm{II})$ in aqueous solution. Materials Science and Engineering $A$ 466, 201-206. DOI: 10.1016/j.msea.2007.02.097.

3. Li, Y.H., Wang, S., Wei, J., Zhang, X., Xu, C., Luan, Z., Wu, D. \& Wei, B. (2002). Lead adsorption on carbon nanotubes. Chem. Phys. Lett. 357, 263-266. DOI: 10.1016/ S0009-2614(02)00502-X.

4. Lu, C. \& Chiu, H. (2006). Adsorption of zinc (II) from water with purified carbon nanotubes. Chemical Engineering Science 61, 1138-1145. DOI: 10.1016/j.ces.2005.08.007.

5. Stafiej, A. \& Pyrzynska, K. (2007). Adsorption of heavy metal ions with carbon nanotubes. Separation and Purification Technology 58, 49-52. DOI: 10.1016/j.seppur.2007.07.008.

6. Li, H.Y., Wang, S., Luan, A., Ding, J., Xu, C. \& Wu, D. (2003). Adsorption of cadmium(II) from aqueous solution by surface oxidized carbon nanotubes. Carbon 41, 1057-1062. DOI: 10.1016/S0008-6223(02)00440-2.

7. Chingombe, P., Saha, B. \& Wakeman, R.J. (2005). Surface modification and characterization of a coal-based activated carbon. Carbon 43, 3132-3143. DOI: 10.1016/j.carbon.2005.06.021.
8. Biniak, S., Pakula, M., Szymanski, G.S. \& Swiatkowski, A. (1999). Effect of activated carbon surface oxygen- and/ or nitrogen containing groups on adsorption of copper(II) ions from aqueous solution. Langmuir 15, 6117-6122. DOI: 10.1021/la9815704.

9. XU, Y., Rosa, A., LIU, X. \& SU, D. (2011). Characterization and use of functionalized carbon nanotubes for the adsorption of heavy metal anions. New Carbon Materials 26 (1), 57-62. DOI: 10.1016/S1872-5805(11)60066-8.

10. Bahgat, M., Farghali, A.A., El Rouby, W.M.A. \& Khedr, M.H. (2011). Synthesis and modification of multi-walled carbon nano-tubes (MWCNTs) for water treatment applications. Journal of Analytical and Applied Pyrolysis 92 (2), 307-313. DOI: 10.1016/j.jaap.2011.07.002.

11. Lu, C., Chiu, H. \& Liu, C. (2006). Removal of zinc(II) from aqueous solution by purified carbon nanotubes: kinetics and equilibrium studies. Ind. Eng. Chem. Res. 45, 2850-2855. DOI: $10.1021 / \mathrm{ie} 051206 \mathrm{~h}$.

12. Li, Y.H., Di, Z., Ding, J., Wu, D., Luan, Z. \& Zhu, Y. (2005). Adsorption thermodynamic, kinetic and desorption studies of $\mathrm{Pb} 2+$ on carbon nanotubes. Wat. Res. 39, 605-609. DOI:10.1016/j.watres.2004.11.004.

13. Vukovic, G.D., Marinkovic, A.D., Colic, M., Risti, M. D., Aleksi, R., Peric-Grujic, A.A. \& Uskokovic, P.S. (2010). Removal of cadmium from aqueous solutions by oxidized and Ethylenediamine-functionalized multi-walled carbon nanotubes. Chemical Engineering Journal 157, 238-248. DOI: 10.1016/j. cej.2009.11.026.

14. AbdelSalam, M., Makki, M.I., Abdelaal, M.Y.A. \& Salametal, M.A. (2010). Preparation and characterization of multi-walled carbon nanotubes/chitosan nanocomposite and its application for the removal of heavy metals from aqueous solution. Journal of Alloys and Compounds 529 (5), 2582-2587. DOI: $10.1016 /$ j.jallcom.2010.11.094.

15. Tarley, C.R., Santos, V.S., Baeta, B.E.L., Pereira, A.C. \& Kubota, L.T. (2009). Simultaneous determination of zinc, cadmium and lead in environmental water samples by potentiometric stripping analysis (PSA) using multiwalled carbon nanotube electrode. Journal of Hazardous Materials 169, 256-262. DOI: 10.1016/j.jhazmat.2009.03.077.

16. Shamspur, T. \& Mostafavi, A. (2009). Application of modified multiwalled carbon nanotubes as a sorbent for simultaneous separation and preconcentration trace amounts of $\mathrm{Au}(\mathrm{III})$ and $\mathrm{Mn}(\mathrm{II})$. Journal of Hazardous Materials 168, 1548-1553. DOI:10.1016/j.jhazmat.2009.03.028.

17. Pillay, K., Cukrowska E. M. \& Coville N. J. (2009). Multi-walled carbon nanotubes as adsorbents for the removal of parts per billion levels of hexavalent chromium from aqueous solution. Journal of Hazardous Materials 166, 1067-1075. DOI:10.1016/j.jhazmat.2008.12.011.

18. Pyrzynska, K. \& Bystrzejewski, M. (2010). Comparative study of heavy metal ions sorption onto activated carbon, carbon nanotubes, and carbon-encapsulated magnetic nanoparticles. Colloids and Surfaces A: Physicochem. Eng. Aspects 362 102-109. DOI:10.1016/j.colsurfa.2010.03.047.

19. Sheng, G., Li, J., Shao, D., Hu, J., Chen, Ch., Chen, Y. \& Wang, X. (2010). Adsorption of copper(II) on multiwalled carbon nanotubes in the absence and presence of humic or fulvic acids. Journal of Hazardous Materials 178, 333-340. DOI:10.1016/j.jhazmat.2010.01.084.

20. El-Sheikh, A.H., Al-Degs, Y., Al-Asad, R.M. \& Sweileh, J.A. (2010). Effect of oxidation and geometrical dimensions of carbon nanotubes on $\mathrm{Hg}$ (II) sorption and preconcentration from real waters. Desalination 270 (3), 214-220. DOI: 10.1016/j. desal.2010.11.048.

21. DAngelo, P., Migliorati, V., Mancini, G. \& Chillemi, G. (2008). A coupled molecular dynamics and XANES data analysis investigation of aqueous cadmium (II). J. Phys. Chem. A 112, 11833-11841. DOI:10.1021/jp806098r. 
22. Allen, M.P. \& Tildesley, D.J. (1987). Computer simulation of liquids. Clarendon Press, Oxford, hardback.

23. Ansari dezfoli, A.R., Adabavazeh, Z. \& Mehrabian, S. (2011). A molecular dynamic simulation investigation into the behavior of water molecules inside carbon nanotubes. Nanomechanics Science and Technology: An International Journal 1, 247-255. DOI: 10.1615/NanomechanicsSciTechnolIntJ.v1.i3.

24. Banerjee, S., Murad, S. \& Puri, I.K. (2007). Preferential ion and water intake using charged carbon nanotubes. Chemical Physics Letters 434, 292-296. DOI:10.1016/j.cplett.2006.12.025.

25. Berendsen, H.J.C., Postma, J.P.M., Van Gunsteren, W.F., DiNola, A. \& Haak, J.R. (1984). Molecular dynamics with coupling to an external bath. J. Chem. Phys. 81, 3684-3690. DOI:10.1063/1.448118.

26. Attard, Ph., Antelmi, D. \& Larson, I. (2000). Comparison of the zeta potential with the diffuse layer potential from charge titration, Langmuir 16, 1542-1552. DOI:10.1021/la990487t. 